\title{
A CRIAÇÃO DE MERCADOS PARA TECNOLOGIAS MENOS POLUIDORAS: O CASO DO BIODIESEL NUMA PERSPECTIVA EVOLUCIONÁRIA
}

\author{
Área temática: Gestão Ambiental
}

\author{
Ednilson Silva Felipe ${ }^{1}$
}

\section{INTRODUÇÃO}

Esse trabalho parte da perspectiva de que o uso mais intensivo de tecnologias menos poluidoras deve estar no centro dos debates sobre o desenvolvimento econômico e das transformações esperadas do século 21. Segue-se daí que o grande salto precisa estar ligado ao emprego de tecnologias que sejam mais amigáveis quanto aos impactos ambientais que provocam. Entretanto, dentro do atual modelo econômico, o uso de tais tecnologias não é nem automático e nem natural. Por outro lado, quanto às questões de demanda do consumidor final, a constatação é que o alinhamento a uma postura de eficiência energética somente pode acontecer se o conjunto de beneficios dessa adoção superar, a princípio, os próprios custos dessas mudanças. Como sugere a IEA (2003, p. 14), "most consumers have little interest in energy issues, per se, but would gladly respond to energy efficiency measures or use renewable fuels as part of a package with features they do care about".

Em relação ao papel do estado, deve-se ter em mente que as políticas públicas devem ser tais que criem estruturas de incentivos que levem à formação de expectativas que sejam favoráveis aos riscos de inovar nesse setor: ou seja, diminuir os níveis de resistências para os investimentos. Nessa ótica, vale dizer que se as transformações na matriz energética na década de 70 foram incentivadas por questões ligadas principalmente aos custos econômicos derivados da instabilidade do petróleo, as motivações atuais estão ligadas à necessidade de redução dos efeitos negativos da atividade econômica, baseada fundamentalmente no uso intensivo de recursos não-renováveis e de significativo impacto ambiental. Por essa ótica, há importante mudança no papel do estado: nas transformações da década de 70 o estado não precisou lidar fortemente com as relutâncias do setor privado quanto à adesão às mudanças, visto que engajamento foi quase automático. $\mathrm{Na}$ presente transformação, entretanto, a principal ação deve ser aquela que leva em conta certa relutância na criação, desenvolvimento e adoção de tecnologias substitutivas, dada a maturidade já consolidada das tecnologias baseadas no uso intensivo de petróleo e seus derivados. Por essa ótica, a adoção mais intensa de produtos/tecnologias alternativas ao uso dos hidrocarbonetos tradicionais só pode ser levada a cabo com a participação incentivadora (e às vezes impositiva) do estado.

Este trabalho trata da seguinte questão: Como podem ser construídas as estruturas de incentivo que levariam à decisões de promover inovações, adoção e difusão e uso de tecnologias menos poluidoras? Como se situam os biocombustiveis nessa lógica e qual o papel do setor público e privado nessa esteira de transformações?

\footnotetext{
${ }^{1}$ Professor do Departamento de Economia da Universidade Federal do Espírito Santo.
} 
Para tanto, o artigo está dividido em três partes. A primeira trata da inovação e desenvolvimento de tecnologias alternativas dentro de uma perspectiva evolucionária. $\mathrm{O}$ item seguinte apresenta alguns dados e políticas sobre o biodiesel na União Européia, principal produtora e nos Estados Unidos, também um grande produtor mundial. $\mathrm{O}$ item três apresenta alguns dados e a política voltada ao desenvolvimento desse óleo no Brasil. O último item apresenta as considerações finais, seguidas das referências.

\section{DESENVOLVIMENTO}

\section{A CRIAÇÃO DE ESPAÇOS PARA TECNOLOGIAS MENOS POLUIDORAS NUMA PERSPECTIVA EVOLUCIONÁRIA.}

Este trabalho assume que o investimento e o uso mais intensivo de tecnologias menos poluidoras e sua inserção na lógica dos mercados competitivos deve levar a dois efeitos positivos: (a) em primeiro lugar, destaca-se os efeitos diretos sobre a produção e consumo de energia no sentido de tornar o sistema energético mais eficiente. Dada a sua dimensão e abrangência, essa deve ser mais fortemente uma meta buscada pelo poder público e (b) em segundo lugar, o uso de novas tecnologias também deve levar os atores de mercado a uma certa curva de aprendizado no sentido de como produzir e usar tais tecnologias mais eficientemente e a custos menores. Isso seria representado pela combinação dos efeitos físicos e de aprendizado que deve criar um impacto real, estimulados a partir dos programas de emprego de tecnologias menos poluidoras. Nesse caso, é preciso observar tanto as diversas dimensões incluídas nessa lógica, quanto perceber o papel do estado para sua consolidação.

\subsection{As diversas dimensões do desenvolvimento e difusão de tecnologias menos poluidoras.}

(a) A dimensão tecnológica

As possibilidades que se abrem às inovações e difusão de novas tecnologias menos poluidoras estão ligadas às especificidades das trajetórias tecnológicas aí envolvidas, que são historicamente determinadas. A idéia aqui é que as decisões anteriores - e a evolução do processo de seleção - e seus resultados condicionam o leque de possibilidades inovações possíveis e que estejam direcionadas aos ganhos de eficiência energética, aumentando ou diminuindo tais possibilidades. O rompimento com essa lógica/trajetória somente seria possivel com alterações tecnológicas de cunho radical, ou seja, saltos tecnológicos que significariam rompimento com a path dependence estabelecida por aqueles regimes.

Não se quer dizer, porém, que a tecnologia já madura não possa contribuir para incrementos na eficiência energética. É fato que o aumento da eficiência energética sempre foi um objetivo perseguido e suas possibilidades sempre exploradas a partir dos condicionantes daquelas características do regime tecnológico. Contudo, tais inovações são eminentemente incrementais e embora sejam importantes, não dão conta de promover saltos tecnológicos que promovam alterações qualitativamente rompedoras daquela relação com as fontes de energia que mais poluidoras para aquelas ambientalmente mais amigáveis. Se esse é um prisma meso-econômico que foca sobre um determinado sistema tecnológico, é preciso, por outro lado, 
analisar a dimensão tecnológica e a racionalidade que prevalecem no âmbito da firma. Seguindo uma ponderação de Gadelha (2002, p. 89) "a empresa privada é a protagonista do processo de inovação que direciona o desenvolvimento capitalista, constituindo um agente ativo que formula estratégias e promove o progresso técnico".

Nessa ótica, sustenta-se que existe um elo necessário entre o desenvolvimento e aplicação de tecnologias mais limpas e as decisões privadas de investimento e de aprendizado tecnológico que acontece no nível da firma. Isso quer dizer que tanto o nivel de aprendizado tecnológico quanto da estrutura de incentivos que podem ser criados para impulsionar tais investimentos precisam ser canalizados à racionalidade econômica que move as decisões empresariais. Nesse caso, o emprego de tecnologias mais eficientes deve ser o resultado racional do agente econômico em termos de ter ponderado os custos comparativos de aprendizado entre as tecnologias alternativas possíveis.

A idéia é que qualquer política pública ou qualquer programa de incentivo precisa levar em conta o aprendizado tecnológico -seu conteúdo, velocidade e limitações que acontece a partir das decisões empresariais, conduzidas por uma lógica econômica de mercado. A inobservância dessa dimensão é condenar a iniciativa ao fracasso.

\section{(b) A dimensão do mercado competitivo}

Essa dimensão parte da perspectiva de que a inovação e adoção das tecnologias menos poluidoras constituem processos mercadológicos onde as decisões são baseadas na racionalidade econômica típica dos agentes. Por esse ângulo, o mercado aparece como ambiente institucional concreto no qual a competição ocorre, sendo o locus do processo de seleção de inovações (Nelson e Winter, 1982). Assim, a competição define o processo de seleção e difusão e condiciona a geração de inovações.

Contudo, diferentemente de outras tecnologias, o desenvolvimento de um mercado para tais inovações não deve acontecer espontaneamente: políticas públicas devem suportar sua criação. Isso é claro porque existe aqui um problema de oferta e de demanda: em termos de ofertas por uma questão de custos, performances e barreiras à entrada. Em termos de demanda, ligado a estrutura de incentivos dos consumidores que não alocam a eficiência energética como prioridade em suas decisões.

\section{(c) A dimensão dos incentivos}

Políticas e programas de incentivo são críticos para aceitação (e emprego) dessas inovações. Enquanto os aspectos tecnológicos e de mercado são profundamente influenciados por decisões privadas, as políticas públicas devem ser tais que cumpram a função de emissoras de sinais ao mercado, influenciando as estruturas de expectativas que são levadas em consideração para as decisões de investimentos. A complementaridade entre o papel do Estado e do setor privado neste caso é latente. A questão aqui é que o sucesso na difusão e uso de tais tecnologias sobre troca aos modelos atuais não se dará se for determinado exclusivamente pelas forças de mercado. 
Dadas essas três dimensões, fica claro que é preciso intensificar os processos de aprendizado para dar conta da interdependência dessas observações. $O$ aprendizado, nesse sentido, precisa ser entendido a partir de duas outras perspectivas: (i) Aprendizado tecnológico: Que se refere aos saltos tecnológicos visando a redução da ineficiência energética e que culmina com sua aplicabilidade no mercado como tecnologia alternativa concorrente. Isto porque "decision makers in industry may judge the initial cost of market learning for a given technology to be too high and involve too much risk" (IEA, 2003, p. 42). (ii) Aprendizado institucional: Que se refere ao aumento da capacidade institucional para ações efetivas que permitam a redução das barreiras de mercado, aumento do fluxo informacional, o estabelecimento de parâmetros claros de eficiência e de uma estrutura de incentivos a alcança-los e a redução dos custos de transação, dada a especificidade da nova tecnologia.

\section{2 - O papel das políticas públicas}

Segue-se, na perspectiva evolucionária, que o Estado possui a capacidade diferenciadora de articular os agentes e instituições em torno de certas trajetóriasmetas de desenvolvimento, o que interfere decisivamente nas possibilidades de convergência que caracteriza um processo evolutivo (Nelson e Winter, 1982). Daí, segue-se que existe uma complementaridade notória entre o papel do estado e do setor privado.

Por essa perspectiva, o sucesso no ciclo 'desenvolvimento - adoção - difusão' de inovações voltadas às tecnologias menos poluidoras não pode ser levada a cabo apenas pelas forças do mercado, por um lado, e não pode prescindir do papel do mercado de selecionador daquelas economicamente viáveis, por outro. Ainda: se o comportamento dos agentes é moldado pelas capacitações adquiridas ao longo do tempo e pelo ambiente em quês estão inseridos, a atratividade para ações inovativas e de investimentos de riscos pode depender da reconfiguração do contexto econômico e institucional, de forma a impulsionar tais investimentos. Novamente como sugere a IEA (2003, p. 11), "governments that value the wider benefits of cleaner and more efficient energy technologies will work in partnership with market to ensure there are real opportunity for technologies to make the difficult transition from laboratory to market". Assim, políticas e programas de incentivo são críticos para aceitação (e emprego) de inovações para tecnologias mais limpas. Enquanto os aspectos tecnológicos e de mercado são profundamente influenciados por decisões privadas, as politicas públicas devem ser tais que cumpram a função de emissoras de sinais positivos ao mercado, incentivando sua utilização.

\section{UMA APLICAÇÃO AOS BIOCOMBUSTÍVEIS E SUA PERSPECTIVA MUNDIAL}

\section{1 - Biodiesel: uma rápida caracterização}

Uma definição básica de biodiesel estaria fundamentada no fato de representar um combustivel renovável, produzido a partir de óleos vegetais ou de gorduras animais, dentre outras matérias primas. No setor de transportes, pode ser usado misturado ao diesel de petróleo ou na sua forma pura. Quando usado em mistura com o diesel de petróleo (em 5-10\% ou 25-30\%) não são requeridas alterações tecnológicas nos motores. Mesmo quando usado sozinho, essas alterações são muito pequenas, o 
que representa uma vantagem em termos de minorar os custos de mudança para uma forma menos impactante ao meio ambiente.

\section{2 - O biodiesel na União Européia: elementos, estatística e política}

O principal mercado produtor e consumidor de biodiesel é a União Européia (UE), que vem fabricando o produto em larga escala desde 1992, principalmente em respostas às sinalizações positivas das instituições da EU quanto ao suporte e políticas de apoio à produção e consumo do combustível, através das diretrizes de ação e legislações específicas.

Há atualmente aproximadamente 120 plantas na EU, produzindo cerca de 5,7 milhões de toneladas anualmente, localizadas principalmente na Alemanha, Itália, Áustria e França (EBB, 2008). Essa produção representa um acréscimo de 16,8\% em relação à produção em 2006. O gráfico 1 apresenta a evolução da produção de biodiesel na EU.

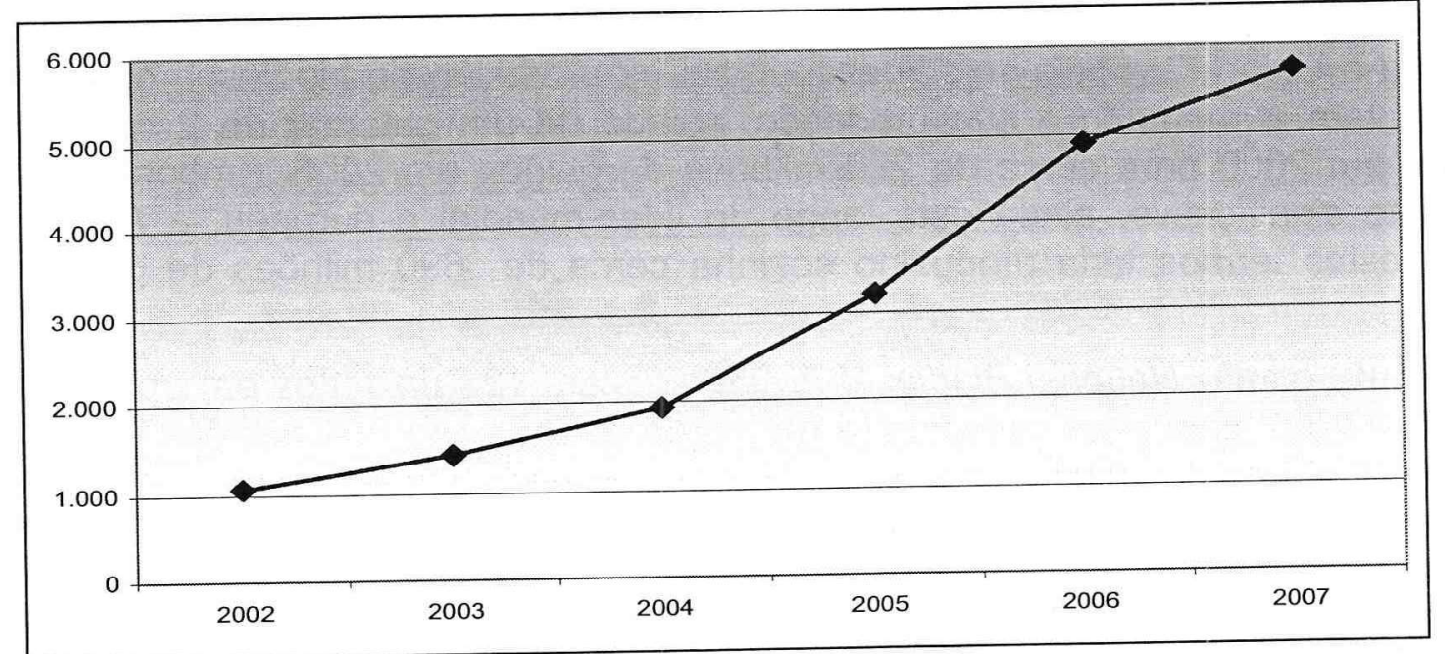

\section{GRÁFICO 1 - Produção de Biodiesel na União Européia 2002-2008}

Fonte: European Biodiesel Board (2008)

A capacidade instalada na EU é de 16 milhões de tonelada, com a Alemanha respondendo por 5,3 milhões dessa capacidade. Em resposta aos incentivos por parte das instituições européias cerca de 40 usinas foram montadas em diversos países do bloco nos últimos dois anos.

Aproximadamente metade da produção de biodiesel europeu está concentrada na Alemanha. De um total de 5,7 milhões de toneladas produzidas em 2007, 2.88 foram produzidas naquele país, que usa como principal matéria prima a canola. O governo alemão concede subsídios de 47 euros para cada 100 litros de biodiesel. Pode-se afirmar que a lógica deste subsídio é a geração e a manutenção de empregos na agricultura, um mecanismo tradicional de incentivo da Política Agrícola Comum Européia. O segundo maior produtor de biodiesel é a França, com uma produção de 872 milhões de toneladas em 2007. A meta do governo francês é triplicar a capacidade de produção interna nos próximos três anos, na intenção de competir com a Alemanha. Sua capacidade de produção atual é de 1,98 milhões de toneladas 
anualmente. Os sistemas produtivos de biodiesel na França são semelhantes aos da Alemanha. Contudo, em termos de comercialização, o combustível francês é fornecido já misturado com o diesel de petróleo, na proporção de $5 \%$ (EBB, 2008). Em terceiro lugar no ranking do biodiesel está a Itália, com uma produção de 363 milhões de tonelada em 2007. A principal matéria-prima utilizada é a colza, que é importada da França e da Alemanha, tendo em vista que a produção interna é insignificante. A capacidade instalada da Itália é de 1,56 milhões de toneladas, considerando também a possibilidade de produção do hidrodiesel.

\section{3 - A produção de biodiesel nos Estado Unidos: elementos, estatística e políticas}

De acordo com o Centro para o Desenvolvimento Rural e da Agricultura (CARD, 2008), os Estados Unidos são importantes produtores de biodiesel, com uma produção interna impulsionada pelos incentivos tarifários e creditícios concedidos pelo governo e pela necessidade de dar vazão aos estoques extras de óleo de soja em vários estados americanos.

Embora a União Européia seja líder mundial na produção de biodiesel, os Estados Unidos tem aumentado a sua produção, saindo de um patamar de 2 milhões de galões em 2000 para cerca de 250 milhões de galões em 2006. Embora seja um aumento significativo, ainda está longe do líder mundial e europeu, a Alemanha, que, nestes termos teria produzido sozinha cerca de 690 milhões de galões em 2007).

De acordo com o National Biodiesel Board, existem 105 unidades em operação no início de 2007 com uma capacidade de produção anual de 864 milhões de galões. Um adicional de 1,7 bilhões de galões capacidade é ainda estimada, se entrar em operação das instalações que estão em construção em 2008. A rápida expansão da produção de biodiesel observada entre 2000 e 2006 foi influenciada por algumas alterações, a partir de 1998, no Energy Policy Act, principalmente pelo apoio e suporte financeiro por parte do Programa de Bioenergia da USDA. Além disso, foi criado um apoio adicional através do American Jobs Creation Act, de 2004 e da Política Energética de 2005.

O Programa de Bioenergia funcionou até 2006 via reembolso financeiro aos produtores de forma a incentivar a produção biodiesel. Embora inicialmente apenas biodiesel fabricado a partir de oleaginosas era elegível para os suportes financeiros, a alteração no projeto, em 2002 alargou a lista de permitidos, incluindo também os subprodutos animais, gorduras, óleos e reciclados de uma origem agrícola. $\mathrm{O}$ American Jobs Creation Act também gera incentivos para a indústria dos biocombustiveis. Nos termos da lei, as empresas que processam as misturas podem reclamar US $\$ 1,00$ por galão de biodiesel fabricado a partir de óleos vegetais virgens ou gorduras animais e US $\$ 0,50$ por galão a partir de óleos e gorduras reciclados misturados com gasóleo. Para receber o crédito fiscal, a empresa é obrigada a utilizar biodiesel como combustível registrado na Environmental Protection Agency.

Em relação ao Energy Policy Act de 2005 a idéia é baixar os custos de produção, fornecendo créditos tributários a uma taxa de US $\$ 0,10$ por galão aos pequenos produtores de biodiesel. $\mathrm{O}$ crédito está disponivel para os primeiros 15 milhões de galóes produzidos por uma planta com capacidade de produção anual de menos de 
60 milhões de galões. Esse projeto, porém, tem prazo determinado e expira no final de 2008.

\section{UMA APLICAÇÃO AOS OS BIOCOMBUSTÍVEIS E A PERSPECTIVA BRASILEIRA}

O governo brasileiro lançou em 2004 o marco regulatório que estabeleceu as condições para a introdução do biodiesel na Matriz Energética Brasileira. A Lei no $11.097 / 2005$, estabelece a obrigatoriedade da adição de um percentual mínimo de biodiesel ao óleo diesel em qualquer parte do território nacional. Esse percentual obrigatório será de $5 \%$ oito anos após a publicação da referida lei, havendo um percentual obrigatório intermediário de $2 \%$ três anos após a publicação da mesma. A adição de $2 \%$ de biodiesel ao óleo diesel consumido no Brasil cria um mercado interno potencial de 1 bilhão de litros em 2008 Para a mistura de $5 \%$ de biodiesel ao diesel consumido, a previsão de consumo de biodiesel salta para 2,4 bilhões de litros em 2013 (ALMEIDA, BOMTEMPO E SILVA, 2007).

Os processos atuais de produção de biodiesel estão concentrados fortemente na reação de transesterificação de óleos vegetais usando etanol anidro como reagente. A figura 1 apresenta as principais matérias-primas usadas na fabricação de biodiesel no Brasil, apontando sua localização predominante.

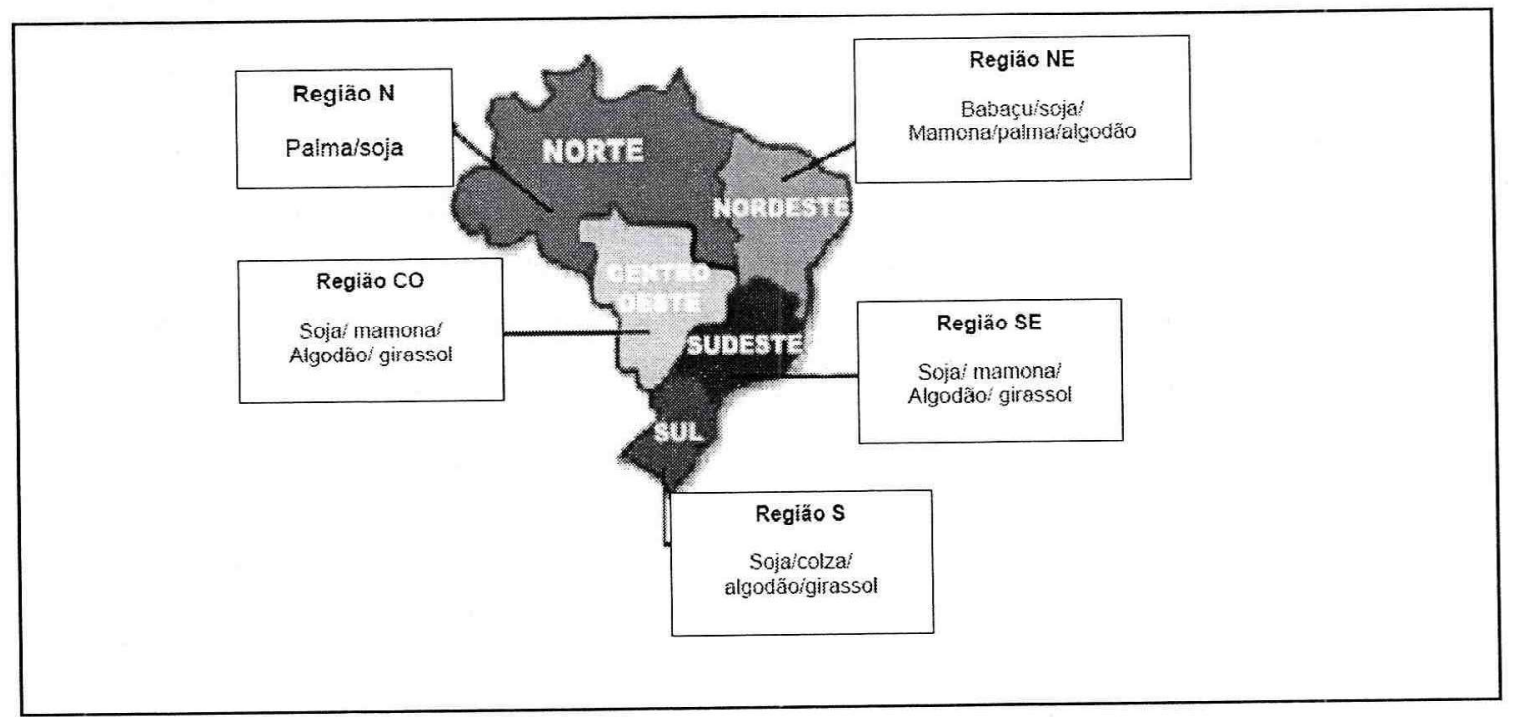

Figura 1: Principais matérias-primas usadas na produção de Biodiesel no Brasil

Fonte: PNPB (2008)

A legislação brasileira que torna compulsória a mistura de $2 \%$ do biocombustível no óleo diesel de petróleo, a partir de 2008, é significante para o estabelecimento e consolidação do mercado de biodiesel no Brasil. Outros incentivos paralelos foram criados em termos do desenvolvimento de pesquisas quanto à utilização de matérias-primas alternativas empregadas.

Numa perspectiva social, a estrutura de incentivos foi desenhada também no sentido de estimular a produção em pequenas propriedades. Para incentivar as empresas 
produtoras de biodiesel a adquirir oleaginosas provenientes de agricultores familiares, o governo oferece isenção fiscal de até $68 \%$ no pagamento do PIS/COFINS que incidiriam sobre a comercialização do biodiesel. Em alguns casos, essa isenção pode ser maior dependendo da região de onda a matéria-prima é comprada. No caso da aquisição de matéria-prima do agricultor não familiar, tem-se apenas $32 \%$ de isenção desses tributos (BIODIESELBR, 2006). Em todos os casos, porém, o biodiesel é isento do pagamento de Imposto sobre Produtos Industrializados (IPI) e da Contribuição de Intervenção no Domínio Econômico (CIDE). Embora o marco institucional que tem sido construído no Brasil seja favorável ao desenvolvimento do mercado de biodiesel, o fato de a produção brasileira apresentar custos elevados, seja por utilização das tecnologias de manejo das oleaginosas ou por causa dos custos logísticos envolvidos, pode ameaçar a competitividade do produto brasileiro.

Nesse caso, a dimensão do aprendizado tecnológico precisa ser observada. Duas questões quanto a isso podem ser colocadas. Em primeiro lugar, as diversas possibilidades ainda abertas de fonte de matérias-primas na produção do biodiesel significam que no estágio atual aqueles mecanismos de mercado que coordenam o processo de seleção das inovações - que sejam economicamente viáveis, tecnologicamente possíveis e institucionalmente incentivadas - ainda não foram acionados. Isso quer dizer que a própria dinâmica de mercado deve tratar se selecionar aquelas formas de produção que sejam mais eficientes e que gerem uma maior expectativa de lucros ao empresário. Como sugerem Almeida, Bomtempo e Silva (2007, p. 22), "the technological and economical diversity in the biodiesel segment is a characteristic of the low level of maturity of this industry in Brazil. We can say the Brazilian biodiesel industry is in the initial phase of its life cycle. Several technological options are in competition for a dominant design that could bring the industry to a cost reduction trajectory."

Em segundo lugar, os custos elevados de produção - e até mesmo de extração da matéria-prima nos casos em que essa etapa ainda é feita de forma rudimentar estão ligados à posição predominante na curva de aprendizado tecnológico. Isso sugere que os incentivos à intensificação do aprendizado em uma tecnologia específica que seja sinalizada, a partir do mercado como mais promissora, deverá diminuir os custos de produção, aumentando a competitividade do produto. Nesse sentido, o reflexo claro é que nem mesmo uma definição da escala de produção eficiente é clara para esse setor no Brasil.

Além disso, mesmo para possibilitar a produção que será necessária para suprimir a demanda a partir do aumento da mistura exigida, algumas questões precisam ser tratadas: a) a aprovação dos novos projetos propostos, garantindo a capacidade instalada necessária para atender ao consumo e possibilitando os ganhos de economia de escala, essencial para as atividades com características de rede; b) a realização de investimentos em pesquisa e desenvolvimento de variedades agrícolas mais aptas à fabricação do biodiesel, o que diminuiria o custo de produção e geraria ganhos de aprendizado tecnológico; c) os incentivos à comercialização dos subprodutos gerados, visando reduzir o custo de produção e aumento do conteúdo renovável da produção; d) criar mecanismos de garantia efetiva ao mercado para o biodiesel, aumentando a confiança na execução da legislação já aprovada. 


\section{COMENTÁRIOS FINAIS}

Os benefícios sociais e ambientais perseguidos pela política para a produção e uso do biodiesel no Brasil forçaram a criação de mecanismos fiscais que incentivassem as decisões empresariais nessa direção. Diversificando um pouco em relação à política da União Européia e dos Estados Unidos, o caso brasileiro se caracteriza pelo forte apelo social e de desenvolvimento regional que está embutido no programa nacional de produção do biodiesel, a ponto de sobrepor e confundir-se com outros programas voltados a agricultura familiar. Se por um lado isso significa o aproveitamento de oportunidades para as políticas de cunho social e fixação de famílias no campo, interfere, em certo sentido, no funcionamento dos elementos de coordenação e seleção e também nas rotas de aprendizado tecnológico que aí estão inseridas. De outro modo, pode-se perceber também uma sobreposição ou mistura entre a política de produção do biodiesel e da política agrícola.

Essas observações dão conta de evidenciar a necessidade de aprendizado institucional que ainda precisa acontecer no caso brasileiro para que a produção e consumo do biodiesel possa tomar patamares significativos, como acontece na UE e Estados Unidos. Por outro lado, o aprendizado tecnológico precisa ser tomado como abrangendo toda a cadeia produtiva. A questão aqui é que os processos produtivos descentralizados como proposto e, em alguns casos, tem se desenvolvidos no Brasil se caracterizam pela falta de organização clara das cadeias de produção aí envolvidas.

\section{REFERÊNCIAS BIBLIOGRÁFICAS}

ALMEIA, E; BOMTEMPO, V., SILVA, C. M. (2007) The performance of Brazilian biofuels:an economic, environmental and social analysis. European Conference of Ministers of Transport joint OECD.

CARD - CENTER FOR AGRICULTURAL AND RURAL DEVELOPMENT (2008) Emerging Biofuels: Outlook of Effects on U.S. Grain, Oilseed, and Livestock Markets. Available http://www.card.iastate.edu/publications/INDEX.ASPX.

EBB - EUROPEAN BIODIESEL BORARD (2008) Statiscit. Avaleable in www.ebbeu.org.

GADELHA, Carlos Augusto Grabois (2002) Estado e inovação: uma perspectiva evolucionista. In : Revista de economia contemporânea. Volume 6. $\mathrm{n}^{0} 02$ julho-dezembro. Instituto de Economia - UFRJ. Rio de Janeiro - RJ. Pg. 85-117

IEA - INTERNATIONAL ENERGY AGENCY (2003) Creating market for clean energy technology. IEA, Paris, France.

NATIONAL BIODIESEL BOARD (2008) Biodiesel bulletins. Various numbers. Available http://www.biodiesel.org/news/bulletin/\#.

NELSON, R.; WINTER, S. (1982) An evolutionary theory of economic change. Harvard University Press.

PNPB - PROGRAMA NACIONAL DE PRODUÇÃO E USO DE BIODIESEL (2007) disponivel em www.biodiesel.gov.br, 2007. 